\title{
Lieber Herr Süßmann!
}

Einen Beitrag zu einer Festschrift anläßlich Ihres 70. Geburtstags vermochte ich leider, altersbedingt, nicht zu schreiben. Aber ein Grußwort möchte ich Ihnen heute zukommen lassen.

Unsere Zusammenarbeit ist nun schon nahezu fünf Jahrzehnte alt. Sie bezog und bezieht sich, wenn ich es so simpel sagen darf, auf das Bemühen, die Quantentheorie zu verstehen.

Die Quantentheorie, als Hypothese von Planck 1900 entworfen, von Einstein 1905 und gründlich von Bohr seit 1911 weitergeführt, hat seit Heisenberg 1925, Schrödinger 1926, v. Neumann 1932 ihre im wesentlichen noch heute gültige mathematische Gestalt erhalten. Mit der Erfahrung ist sie seither, wo immer sie überprüfbar war, im Einklang. Als ich 1933 bei Heisenberg promoviert hatte, hatte auch ich gelernt, sie auf Erfahrungsdaten anzuwenden. Aber was die Beschreibung der Natur durch diese mathematische Struktur bedeutete, war mir ein Rätsel. Seitdem, also nun seit über sechzig Jahren, hatte ich die Sehnsucht und auch die Hoffnung, auf diese Frage eine Antwort zu finden, vielleicht selbst auszuarbeiten. Meine mathematischen Fähigkeiten haben dafür nie ausgereicht, und ich spürte das. Darum bedurfte ich stets der Zusammenarbeit mit mir hierin überlegenen Physikern. Und vielleicht der Früheste von diesen waren Sie. Ich weiß nicht mehr ganz genau, in welchem meiner Göttinger Jahre (1946-1957) wir uns begegnet sind. Wir sprachen jahrelang miteinander, und in der Arbeit über „Komplimentarität und Logik III“ (1958), von uns beiden und Scheibe verfaßt, legten wir unsere Deutung vor. Seitdem blieben wir über die dort angeschnittenen Fragen in Kontakt. Unser gemeinsamer Wohnort, nach Göttingen und Hamburg jetzt seit langem München, ermöglichte uns das mündliche Gespräch. Daß wir das Deutungsproblem der Quantentheorie gelöst hätten, wage ich, so schlicht gesagt, nicht zu behaupten. Aber ich meine, wir sind weitergekommen, nicht nur als wir damals waren, sondern auch weiter als die heute verbreiteten Ansichten über dieses Problem. Mein Geburtstagsgruß eines Sechsundachtzigjährigen auch einem nun Siebzigjährigen ist nicht nur ein Rückblick. Er wagt eine Hoffnung auf eigene Fortschritte in diesem Leben zu enthalten.

Ihnen also hoffnungsvolle gute Wünsche

Ihr Carl Friedrich Weizsäcker Starnberg, November 1998 